\title{
Structural Design and Mechanical Properties Analysis of Bamboo-wood Cross-laminated Timber
}

\author{
Chao Li, Xilong Wang, and Yizhuo Zhang * \\ To explore the overall mechanical properties of bamboo-wood composite \\ cross-laminated timber (BCLT), a simulation model of BCLT mechanical \\ behavior based on the solid element was established using the finite \\ element software ABAQUS. The actual four-point bending experiment was \\ compared and analyzed with the finite element numerical simulation. The \\ total curve error coefficient of the BCLT specimen at 18-mm displacement \\ was 0.2988 while the interval was $0.5 \mathrm{~mm}$. The error coefficient was \\ 0.0178 when the maximum load was reached, and the minimum error \\ coefficient was 0.0015 at $12 \mathrm{~mm}$ of displacement. Analysis of the influence \\ of material parameters, meshing density, and material arrangement on the \\ final stress distribution indicate that the difference in the elastic parameters \\ of the material greatly influence the final stress distribution, and the \\ arrangement and combination of materials also have an effect on the \\ overall mechanical properties of the BCLT board. The combination CLT1- \\ 2-1 (i.e., the upper and lower layers of the bamboo are Arrangement 1 and \\ the hemlock is Arrangement 2) have a maximum load of $57682 \mathrm{~N}$ and a \\ maximum stress of $103.9 \mathrm{MPa}$.
}

Keywords: Cross-laminated timber; Bamboo and wood composite; Bending behavior analysis; Four-point bending experiment; Finite element simulation

Contact information: Northeast Forestry University, Harbin, 150040, China;

*Corresponding author: zhangyz@nefu.edu.cn

\section{INTRODUCTION}

Cross-laminated timber (CLT) is a new type of wood structural material. It is a solid wood board made of timber or structural composite sheets with an orthogonal $\left(90^{\circ}\right)$ staggered assembly and is pressed by structural adhesives (FPInnovations 2011). It has the potential of substituting cement or steel (Bejtka 2011; Brandner et al. 2016). In addition, CLT has excellent fire resistance, similar to the characteristics of the structure of heavy wood. In the event of fire, the surface layer of CLT wood carbonizes slowly at a certain rate, and at the same time, it can maintain its internal original structural strength for a long time (Buchanan 2000; Frangi et al. 2010). As a new type of green building material, CLT has excellent performance and a relatively low cost. It can be used as roofs, floors, doors, windows, partition walls, and many other applications (Chen 2009). The research and development of CLT has important practical significance and application prospects for promoting the efficient utilization of wood resources and realizing the rational allocation of resources in China's plantations.

The modulus of elasticity (MOE), the modulus of rupture (MOR), and shear strength are important properties of CLT plates, and they have an important influence on the structural design of CLT floors or roofs. The bending test of CLT plates in practical experiments as well as the modeling and simulation of CLT plates by finite element 
software can better analyze and predict the overall mechanical properties of CLT plates (Schneider et al. 2015; Sebera et al. 2015; Pina et al. 2019).

He et al. (2018) studied the out-of-plane bending properties and compression properties of the Canadian hemlock CLT plate, where the mechanical properties of the CLT plate in the primary and secondary strength directions were obtained through experimental tests, and a numerical model was established to predict the bending stiffness of the CLT plate. The results showed that the performance of Canadian hemlock CLT board is the same as other common wood varieties (Spruce-pine-fir (SPF) lumber or Douglas fir-Larch lumber) (He et al. 2018). Sikora performed bending and shear tests on the spruce CLT plate to obtain the effect of the plate thickness on the mechanical properties of the spruce CLT plate. The overall trend is that the bending strength and shear strength will decrease as the plate thickness increases (Sikora et al. 2016). Gong et al. (2018) calculated the equivalent bending stiffness and moment of CLT based on mechanical connection theory, composite laminate theory, shear analogy theory, and simple design method. Their study verified the accuracy of theoretical predictions through actual measurements, and screened suitable prediction methods (Gong et al. 2018). Yao predicted the mechanical properties of the effective bending stiffness and bending strength of the three-layer CLT plate of hemlock using the mechanical composite beam theory and studied the deflection and bearing of the three-layer CLT plate of hemlock in practical engineering applications. The structural properties, including bending moment and natural frequency of vibration, show that the two-level CLT effective bending stiffness, bending strength, and vibration performance can meet the needs of practical engineering applications (Yao et al. 2018). Wang et al. (2014) studied the mechanical properties of composite laminated plywood of different tree species of Pinus citigensis, Pinus radiata, and Poplar. It was concluded that poplar is placed in the core layer, and the composite tree CLT with good mechanical properties, such as Citi pine, is formed on the surface layer. The flexural modulus and shear strength of poplar CLT can be significantly improved by this composite method. However, few studies have focused on the bending properties of CLT boards made of bamboo (Wang et al. 2014).

Bamboo is widely distributed in southern China. It is a type of natural material for sustainable development. It can be harvested in 3 to 5 years. It is widely used in southern China. Bamboo has the characteristics of high strength, high hardness, good toughness, wear resistance, and biodegradability, but it also has the disadvantages of a small diameter, low yield, and low processing efficiency. Bamboo wood-based panels in China, including bamboo-wood composite panels, have a low utilization ratio and low added value in the production process. Statistics show that the bamboo direct utilization ratio of bamboo floor is only $20 \%$ to $25 \%$, and bamboo utilization ratio of bamboo laminated board is $50 \%$. The low utilization rate of bamboo is due to the structural properties of bamboo pole itself as well as the unreasonable product structure and improper processing technology (Jiang et al. 2002). Flattened bamboo is a new type of engineering product. The bamboo tube is cut off, mechanically processed to remove the inner and outer sections (bamboo green and bamboo yellow), and the seam is opened. After high temperature softening $\left(90^{\circ}, 5-10\right.$ mins), it is sent to the unfolding mold and flattened to obtain the unfolded flat bamboo, and the unfolded surface has no visible cracks. Compared with the flat-paneled semi-bamboo deployment method, the obtained bamboo sheet width is doubled or more (Fang et al. 2018).

Bamboo composite CLT (BWCLT) is a new product that is made of flattened bamboo and structural boards with orthogonal $\left(90^{\circ}\right)$ staggered assembly and pressed by structural adhesives. Through scientifically determining the combination form and gluing 
process, the product's internal and external quality could be improved, and the bamboo utilization ratio could be increased. The purpose of this study is to investigate the influence of element elastic parameters on the overall mechanical properties of BCLT, and to obtain the optimal design model of BCLT.

\section{EXPERIMENTAL}

\section{Materials}

\section{Bamboo}

Phyllostachys pubescens with an age of 6 years, was produced in Chongyi County, Jiangxi Province, China. It was made of bamboo board formed by the flattening bamboo process (see Fig. 1). Its length was $1280 \mathrm{~mm}$, width was $135 \mathrm{~mm}$, and thickness was $8 \mathrm{~mm}$. After being planed, the thickness of the flat bamboo changed from $8 \mathrm{~mm}$ to $6 \mathrm{~mm}$. It had good physical and mechanical properties, including a small coefficient of water absorption and low expansion, and exhibited non-cracking, and non-deformation. According to the requirements of GB/T1931 (2009) and GB/T1933 (2009), its moisture content and density were $6.56 \%$ and $0.617 \mathrm{~g} / \mathrm{cm}^{3}$, respectively. The average tensile strength of the bamboo sheets was $107.40 \mathrm{MPa}$, and the compressive strength was $81.64 \mathrm{MPa}$. The shrinkage of bamboo was small, but the elasticity and toughness were high. The tensile strength and compressive strength (i.e., the strength limit) of the grain were 2.5 times and 1.5 times that of the Chinese fir, respectively.

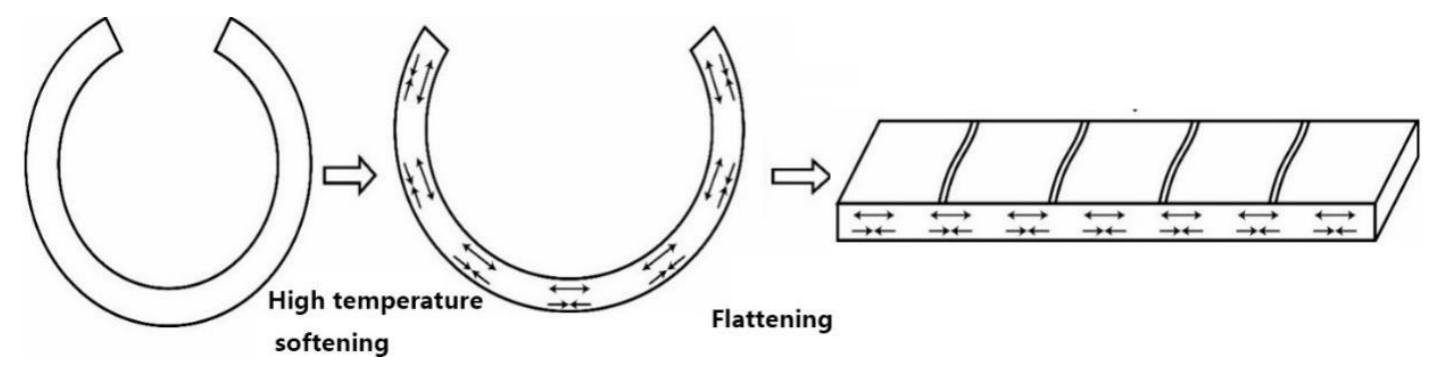

Fig. 1. Flattening bamboo production process

\section{Hemlock}

Canadian hemlock has an air-dry density of $0.47 \mathrm{~g} / \mathrm{cm}^{3}$ and an average moisture content of $15 \%$. Canadian iron fir is fine and moderate in hardness, with high flexural strength and durability. The average compressive strength of the grain is $55 \mathrm{MPa}$. After processing, the size of Canadian hemlock was $1280 \mathrm{~mm} \times 140 \mathrm{~mm} \times 20 \mathrm{~mm}$. After being planed, its thickness changed from $20 \mathrm{~mm}$ to $15 \mathrm{~mm}$.

\section{Methods}

The schematic diagram of the research process is shown in Fig. 2. BCLT specimens were prepared, and bending experiments were carried out. The results show that the performance of bamboo-wood-bamboo CLT specimens (BWBCLT) was better than that of wood-bamboo-wood CLT specimens (WBWCLT). So only BWBCLT was used in finite element simulations. 


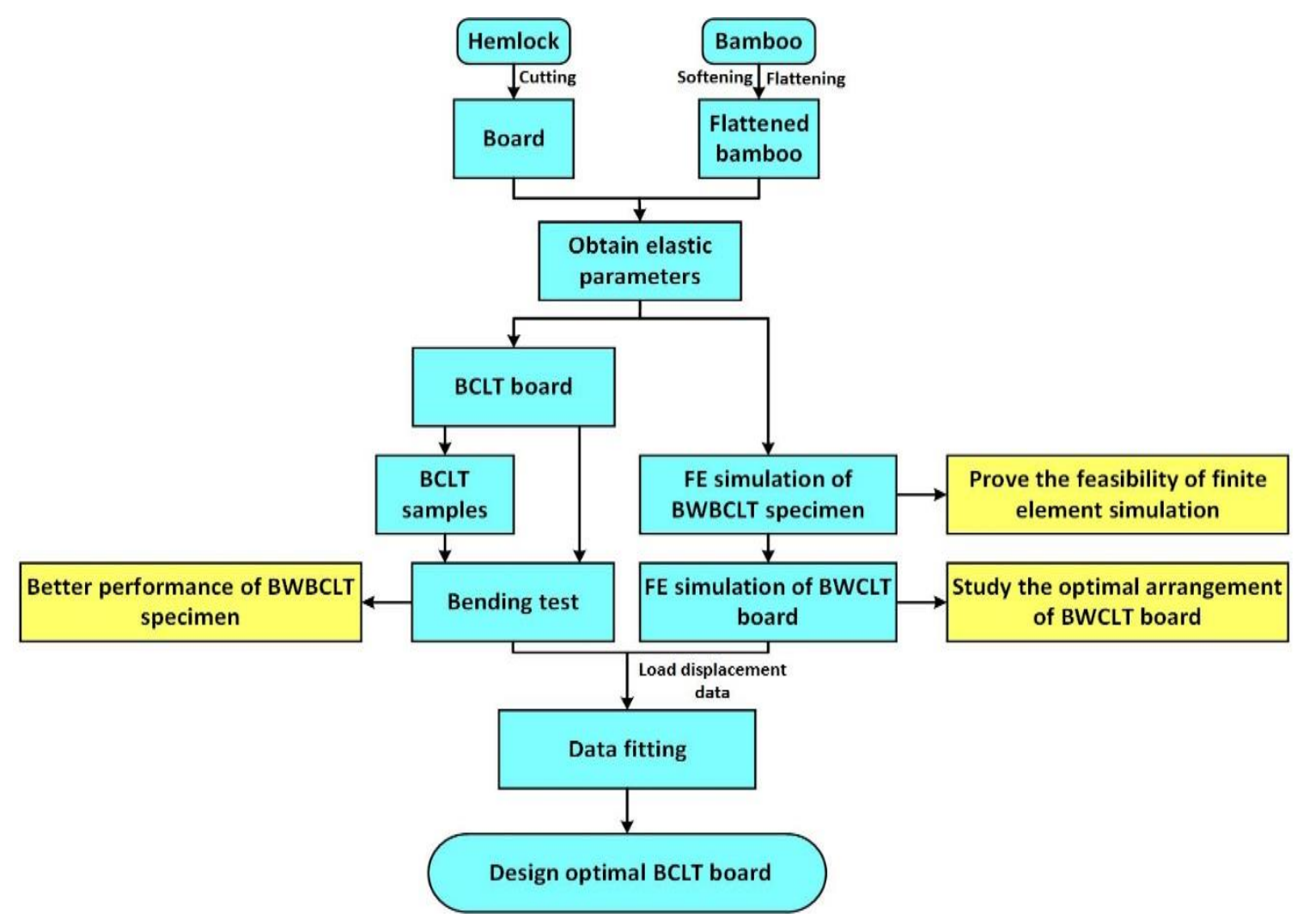

Fig. 2. Schematic diagram of research process

\section{Mechanical Properties of BCLT Samples}

Samples bending experiment

Each of the initial specimens was cut into seven resulting CLT specimens, as shown in Fig. 3. According to the Chinese national standard GB/T 17657 (2013), the four-point bending test method was adopted in the bending test process, as shown in Fig. 4. The height of the BWB sample was $28 \mathrm{~mm}$, and the length of the sample was $644 \mathrm{~mm}$, which was 23 times the height. The distance between the two supporting rolls was $588 \mathrm{~mm}$, which was 21 times the height of the samples, and the two loading rolls took $1 / 3$ of the spacing of the supporting rollers (i.e., $196 \mathrm{~mm}$ ). The thickness of the WBW sample was $36 \mathrm{~mm}$, the length of the sample was $828 \mathrm{~mm}$, the spacing of the supporting rolls was $756 \mathrm{~mm}$, and the spacing of the loading rolls was $252 \mathrm{~mm}$.

A TENSON micro-computer controlled electronic universal mechanical testing machine (WDW-50; TIANCHEN Testing Machine Co., JiNan, China) was used in the bending test. A $50 \mathrm{kN}$ load cell was used in the universal mechanical testing machine to record the load during testing.

The loading process was performed by a load controller, and load was applied to the samples until samples were damaged and failed (when the load decreased 40\%) with a loading speed of $10 \mathrm{~mm} / \mathrm{min}$. The samples started to break when the maximum load was applied. During the measurements, the load-displacement data at mid-span was recorded using a data logger connected to a computer with 10 acquisitions per second $(10 \mathrm{~Hz})$. It took 2 to 3 min to test each sample. 

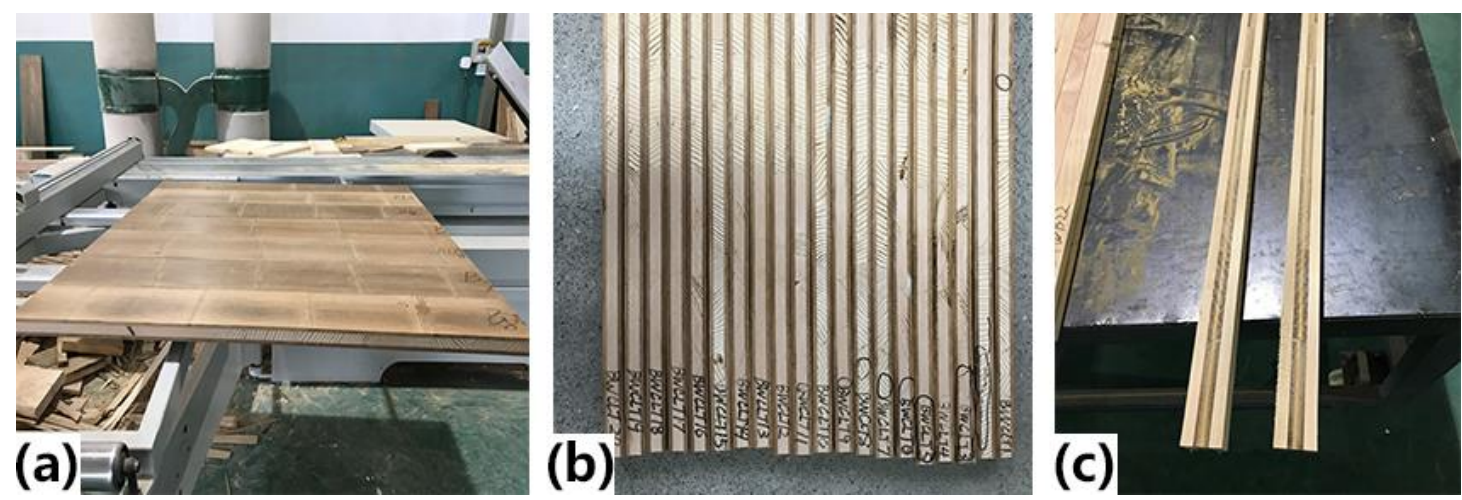

Fig. 3. BCLT samples: (a) BCLT board, (b) BWBCLT, (c) WBWCLT
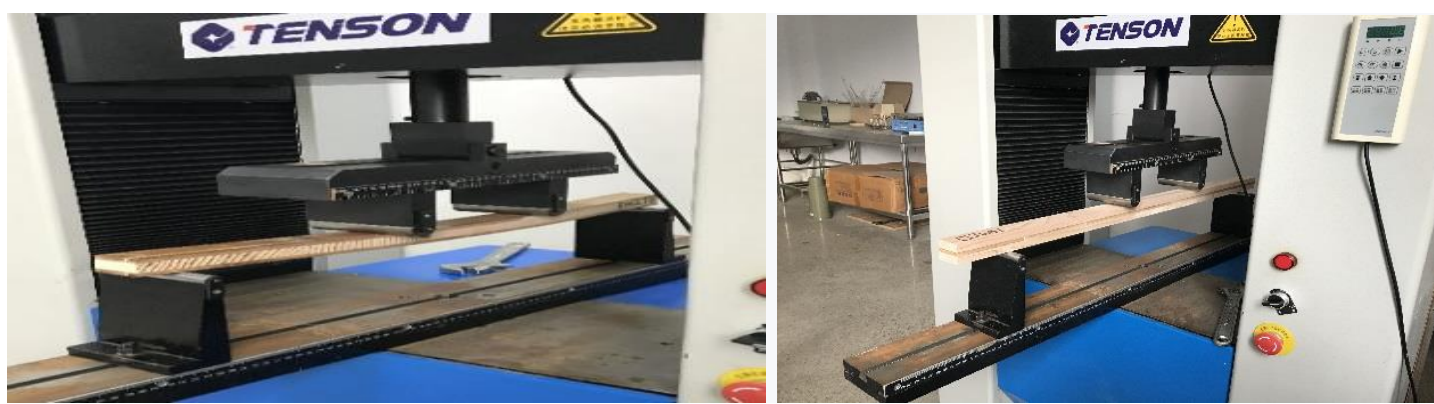

Fig. 4. Samples bending test

After the bending test, the MOE and MOR measurements were taken according to GB/T 17657 (2013). The flexural modulus and static bending strength of the CLT sample were calculated using Eqs. 1 and 2.

$$
\begin{aligned}
& \text { MOE }=23 \Delta P l^{3} / 108 b t^{3} \Delta y \\
& \text { MOR }=F_{\text {max }} l / b t^{2}
\end{aligned}
$$

where $\Delta P$ is the load increment before the tested samples reach their elastic limit $(\mathrm{N}), \Delta y$ is the deflection at the mid-span cross-section $(\mathrm{mm}), F_{\text {max }}$ represents the maximum load in the whole bending test process $(\mathrm{N}), l$ is the distance between two supports, and $b$ and $h$ are the width $(\mathrm{mm})$ and the height $(\mathrm{mm})$ of the tested samples, respectively.

\section{Bending simulation based on Finite element}

Similarly, in ABAQUS (Shanghai Jiangda Technology Company, Abaqus2016, Shanghai, China), the numerical model of the BWB samples with the same specification was established. After establishing the model, the material parameters of the model were set. Two cylinders above the model represented loading rolls in four-point bending. A downward 15-mm displacement was loaded on the cylinder. The lower cylinder included the two supporting rolls, and the four cylinders were all set as discrete rigid bodies. For better convergence, the initial incremental size was set to 0.001 , the minimum increment size was set to $1 \mathrm{e}-10$, and the maximum increment size was set to 1 . The maximum number of increments was 100,000 . The global size was $4 \mathrm{~mm}$. Then, a hexahedron structure was used to divide the grids, and the element type was C3D8R (8-node linear brick, reduced integration, hourglass control). Finally, a "job" was set up to simulate the bending 
process, and the mechanical properties of the bamboo-wood composite were analyzed based on the simulation results.

\section{Mechanical Properties of BCLT Board}

Numerical simulation of BCLT board

Bamboo has similar material properties to wood, and wood finite element calculations can be simplified to orthotropic materials. Orthotropic materials have nine independent engineering constants, namely elastic modulus E1, E2, and E3 in three directions, shear modulus G12, G23, and G31, and Poisson's ratio V12, V23, and V31. The preliminary research group determined the elastic constant of bamboo using electric measurements and the static bending method (Li et al. 2015; Xie et al. 2018). The electrical measurement method mainly measured the shear modulus and Poisson's ratio, and the static bending method measured the flexural modulus. The elastic constant of bamboo is shown in Table 1. The elastic constant of the hemlock is shown in Table 2.

Table 1. Bamboo Elastic Constant

\begin{tabular}{|c|c|c|c|c|c|c|c|c|c|}
\hline \multicolumn{4}{c}{ Elastic Modulus (MPa) } & \multicolumn{3}{c}{ Poisson Ratio } & \multicolumn{3}{c}{ Shear Modulus (MPa) } \\
\cline { 2 - 10 } & E1 & E2 & E3 & v12 & v13 & v23 & G12 & G13 & G23 \\
\hline 1 & 4876 & 1745 & 1185 & 0.278 & 0.288 & 0.568 & 575 & 568 & 328 \\
\hline 2 & 6273 & 1755 & 1353 & 0.26 & 0.286 & 0.593 & 600 & 436 & 378 \\
\hline 3 & 7610 & 1865 & 1138 & 0.265 & 0.235 & 0.598 & 562 & 655 & 326 \\
\hline 4 & 2841 & 1488 & 1094 & 0.239 & 0.302 & 0.555 & 551 & 426 & 305 \\
\hline 5 & 8653 & 1871 & 965 & 0.302 & 0.319 & 0.595 & 545 & 707 & 279 \\
\hline 6 & 5311 & 1746 & 1377 & 0.322 & 0.298 & 0.499 & 619 & 616 & 353 \\
\hline 7 & 3938 & 1500 & 1129 & 0.247 & 0.315 & 0.568 & 574 & 436 & 310 \\
\hline AV & 5643 & 1710 & 1177 & 0.273 & 0.291 & 0.568 & 575 & 549 & 325 \\
\hline SD & 2032 & 160 & 145 & 0.029 & 0.027 & 0.034 & 26.4 & 116 & 32.5 \\
\hline CV\% & $36.01 \%$ & $9.18 \%$ & $12.34 \%$ & $10.91 \%$ & $9.58 \%$ & $6.09 \%$ & $4.60 \%$ & $21.25 \%$ & $9.98 \%$ \\
\hline
\end{tabular}

Note: $\mathrm{AV}$ is Average, SD is standard deviation, and CV is coefficient of variation

Table 2. Hemlock Elastic Constant

\begin{tabular}{|c|c|c|c|c|c|c|c|c|c|}
\hline \multicolumn{4}{c}{ Elastic Modulus (MPa) } & \multicolumn{3}{c}{ Poisson Ratio } & \multicolumn{3}{c|}{ Shear Modulus (MPa) } \\
\cline { 2 - 10 } & E1 & E2 & E3 & v12 & v13 & v23 & G12 & G13 & G23 \\
\hline 1 & 13658 & 906 & 735 & 0.522 & 0.66 & 0.66 & 555 & 804 & 69 \\
\hline 2 & 9467 & 856 & 725 & 0.53 & 0.656 & 0.59 & 515 & 894 & 63 \\
\hline 3 & 12129 & 890 & 731 & 0.51 & 0.634 & 0.61 & 521 & 860 & 68 \\
\hline 4 & 10995 & 872 & 712 & 0.542 & 0.682 & 0.65 & 550 & 838 & 64 \\
\hline 5 & 12820 & 881 & 726 & 0.526 & 0.658 & 0.64 & 535 & 849 & 66 \\
\hline 6 & 11686 & 872 & 729 & 0.52 & 0.651 & 0.57 & 505 & 884 & 62 \\
\hline 7 & 12672 & 879 & 728 & 0.537 & 0.674 & 0.655 & 553 & 827 & 65 \\
\hline AV & 11918 & 879 & 726 & 0.526 & 0.659 & 0.625 & 533 & 850 & 65.2 \\
\hline SD & 1376 & 15.7 & 7.23 & 0.01 & 0.015 & 0.035 & 20.1 & 31.5 & 2.56 \\
\hline CV\% & $11.54 \%$ & $1.78 \%$ & $0.99 \%$ & $2.04 \%$ & $2.36 \%$ & $5.63 \%$ & $3.77 \%$ & $3.70 \%$ & $3.92 \%$ \\
\hline
\end{tabular}

Note: AV is Average, SD is standard deviation, and CV is coefficient of variation 
In ABAQUS, a finite element numerical model of BWCLT board was established. There were 21 units in one whole board, which included upper, middle, and lower layers, and each layer had seven units. Each unit contained inputs for 9 engineering constants and two adjacent layers of orthogonal $\left(90^{\circ}\right)$ staggered combinations. There were two arrangements: Arrangement No. 1 was to set the MOE of the central units to the maximum (i.e., the maximum value of E1 in the table), and then it was decreased to both sides as shown in Fig. 5(a). Arrangement No. 2 was the opposite, which set the MOE of the central unit to the minimum (i.e., the minimum value of $\mathrm{E} 1$ in the table), and increased it to both sides in turn as shown in Fig. 5(b). Each layer was given an arrangement (e.g., the upper and lower plates were assigned to Arrangement No. 1 and the intermediate layer was assigned to the Arrangement No. 2 to form the combination CLT1-2-1). Eight CLT combinations were formed by varying the different arrangements.

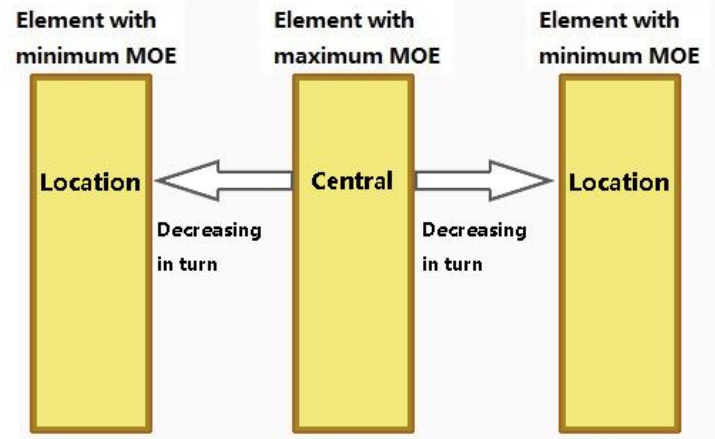

(a)

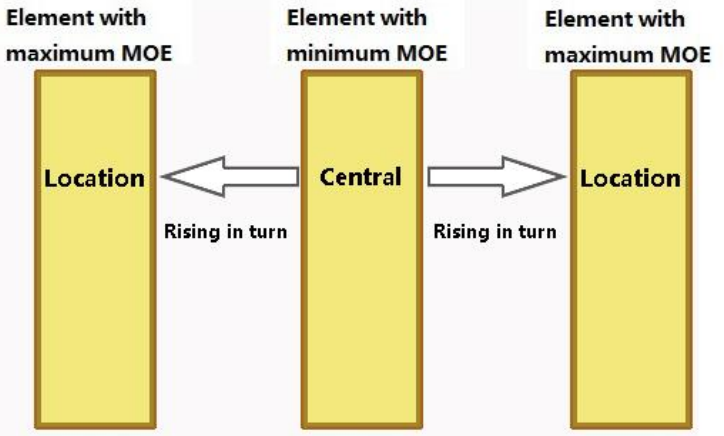

(b)

Fig. 5. Arrangement; (a) Arrangement No. 1 and (b) Arrangement No. 2

The global dimension of the finite element bending simulation mesh was $12 \mathrm{~mm}$, and the maximum deviation factor in the curvature control was 0.1 . The part of the CLT numerical model that was in contact with the cylinder was subdivided by local mesh. The local size was set to $4 \mathrm{~mm}$, and the maximum deviation factor was also 0.1 . After the final mesh division was completed, 24,948 cells were formed. If the local mesh was not subdivided, and the global size of $4 \mathrm{~mm}$ was only set to divide the mesh, the final mesh would reach 426,888 elements. The difference between them would be 400,000 elements, which shows that the amount of calculation and analysis time can be reduced by local mesh subdivision.

\section{BCLT Design and Bending Test}

The whole manufacture process of BCLT board is shown in Fig. 6. First, the bamboo and hemlock were finished by planing and cutting. Then, the board was glued with phenol-resorcinol-formaldehyde (PRF) adhesive and assembled in a staggered fashion. To prevent product deformation and reduce the cost of the adhesive, the lateral layer of the CLT product currently produced was not glued, and there were gaps between the laminates. Studies have shown that the average width of the transverse layer gap is $2 \mathrm{~mm}$. The maximum gap width allowed in the European CLT product standard EN 16351 (2015) is 6 mm (Dias et al. 2007; Wang et al. 2016). The presence of these gaps also influences the rolling shear properties of the CLT transverse layer. Wang et al. (2016) studied the effect of the gap width $(0 \mathrm{~mm}, 2 \mathrm{~mm}, 4 \mathrm{~mm}$, and $6 \mathrm{~mm})$ between the side of the CLT transverse layer and the transverse layer on the rolling shear performance. The results showed that the 
glue coating on the side and the gap width between the panels have significant effects on the rolling shear strength, but not on the rolling shear modulus. When the gap width is more than $2 \mathrm{~mm}$, the influence on the rolling shear strength can be neglected (Wang et al. 2018). The CLT board is pressurized after the gluing is completed. Because the CLT uses a coldcuring structural adhesive, the pressurization is generally higher than the temperature of 15 ${ }^{\circ} \mathrm{C}$, which can significantly reduce the gap between the units. The general CLT pressure standard is adopted, with four sides pressurized, the vertical pressure is $0.6 \mathrm{MPa}$ to 1.0 $\mathrm{MPa}$, and the lateral pressure is $0.27 \mathrm{MPa}$ to $0.55 \mathrm{MPa}$. Finally, the bamboo-wood composite CL board was cut into the same size as the numerical model with dimensions of $910 \mathrm{~mm} \times 910 \mathrm{~mm} \times 28 \mathrm{~mm}$ as shown in Fig. 7. Each layer of the panel contained a gap of $2 \mathrm{~mm}$ between adjacent bamboo boards.

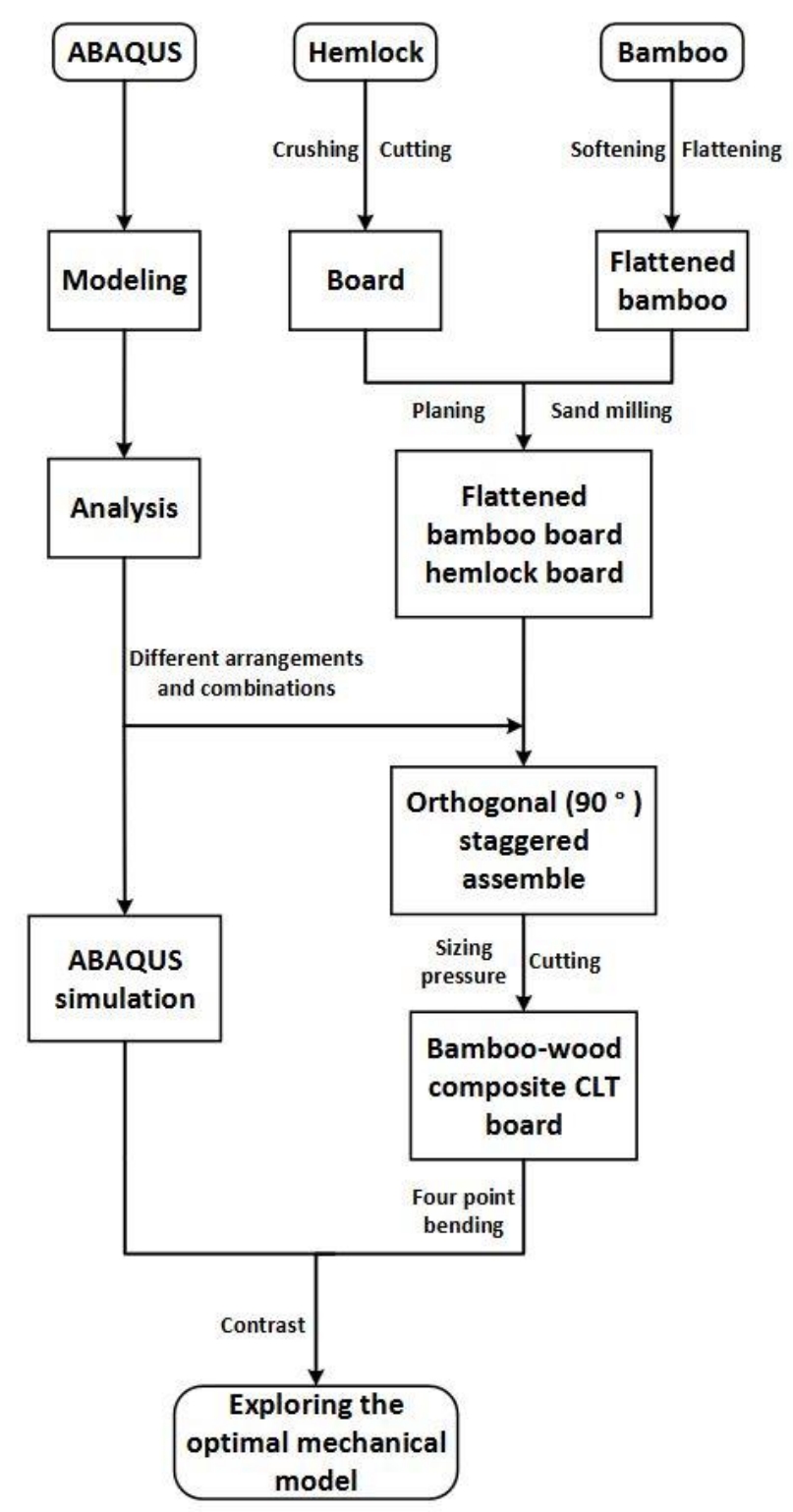

Fig. 6. Diagram of design process of BCLT board 

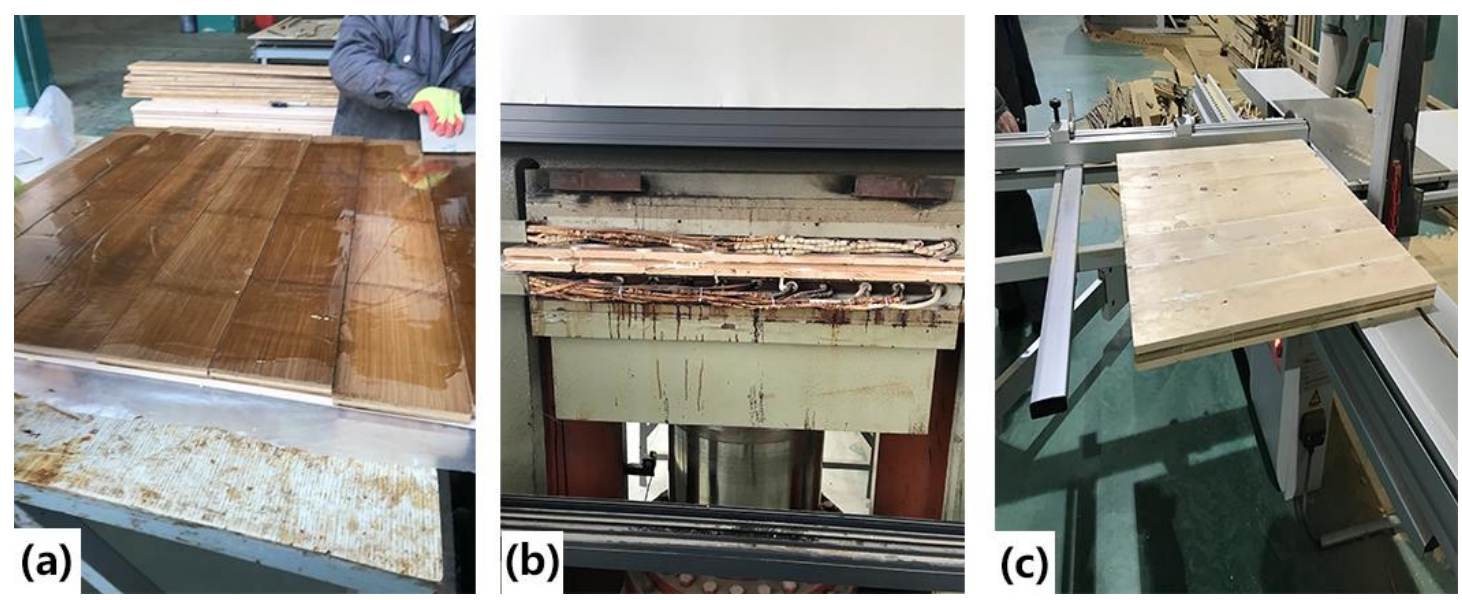

Fig. 7. Process of making the BCLT board: (a) sizing, (b) pressure, and (c) cutting into the boards

\section{Data Fitting}

Steps were taken to better compare and calculate the error of the results between the actual experiment and the finite element simulation. First, the load-displacement curve data of BCLT samples was fitted by TableCurve 2D (TableCurve 2D, Systat Software Inc, v5.01, San Jose, CA, USA), and the fitting functions were obtained as shown in Fig. 8. The correlation of the fitting function Y1 (Eq. 3) of the actual experiment was 99.95\%, and the correlation of the fitting function y1 (Eq. 4) of the finite element simulation was $99.99 \%$. Second, the load-displacement curves of BWCLT boards were fitted, and the fitting functions were obtained. The correlation of fitting function Y2 (Eq. 5) was 99.84\%, and the correlation of fitting function y2 (Eq. 4) was $99.99 \%$. Equation y2 and y1 are the same, but their coefficients are different.

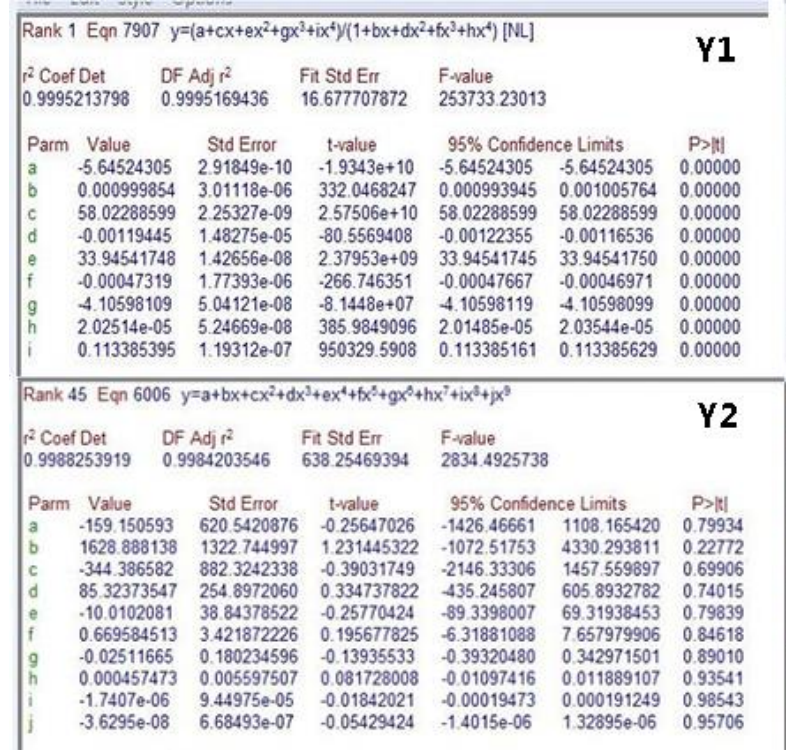

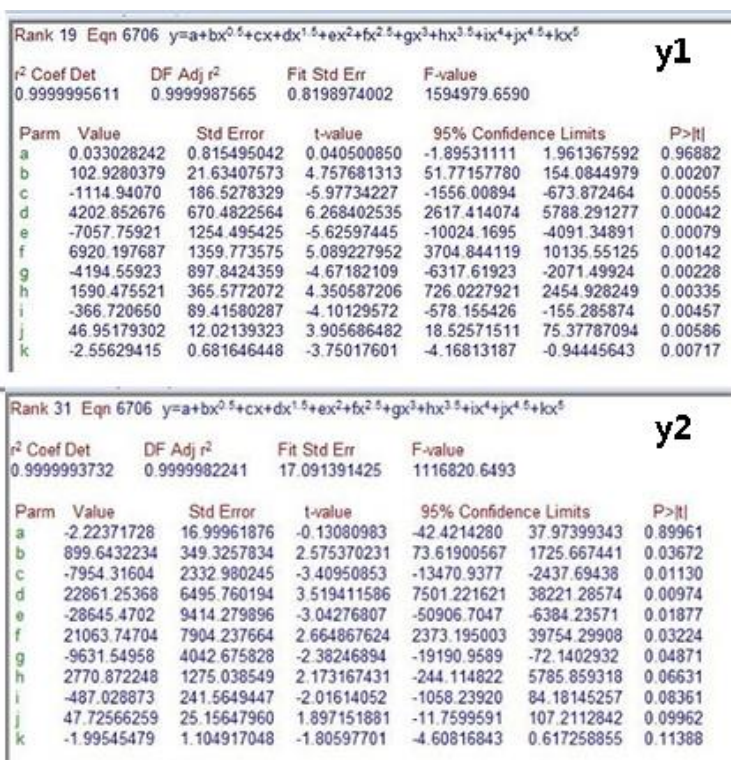

Fig. 8. The fitting functions.

$$
\mathrm{Y} 1=\left(\mathrm{A}+\mathrm{Cx}+\mathrm{E} x^{2}+\mathrm{G} x^{3}+\mathrm{I} x^{4}\right) /\left(1+B x+D x^{2}+F x^{3}+H x^{4}\right)
$$




$$
\begin{gathered}
\quad \mathrm{y} 1(\mathrm{y} 2)=\mathrm{a}+\mathrm{b} x^{0.5}+c x+d x^{1.5}+e x^{2}+f x^{2.5}+g x^{3}+h x^{3.5}+i x^{4}+j x^{4.5}+ \\
\mathrm{Y} 2=\mathrm{A}+\mathrm{B} x+C x^{2}+D x^{3}+E x^{4}+F x^{5}+G x^{6}+H x^{7}+I x^{8}+J x^{9}
\end{gathered}
$$

In Eqs. 3, 4, and 5, all the coefficients in the equation are numerical values.

\section{RESULTS AND DISCUSSION}

\section{Mechanical Properties of BCLT Samples}

Bending results

A four-point bending test was performed on the BCLT sample on a universal testing machine to obtain the MOE, MOR, and maximum load of the CLT, and the data were integrated in Table 3. The average MOE of bamboo was $5640 \mathrm{MPa}$, and that of hemlock was $11,920 \mathrm{MPa}$. The average MOE of the BWBCLT was $9550 \mathrm{MPa}$, and that of WBWCLT was $6040 \mathrm{MPa}$. The MOE of BCLT samples was closer to that of core wood. The average maximum load of BWBCLT and WBWCLT differed by $236 \mathrm{~N}$. After the actual bending experiments, BCLT samples showed varying degrees of damage, as shown in Fig. 9. When the CLT sample was bent, the upper layer of the section was the compression zone, and the lower layer was the tension zone. The result showed that placing the bamboo on the surface layer greatly improved the mechanical properties of the CLT material. The failure mode of BWBCLT was the rolling shear of hemlock and the surface of the bamboo was in good condition as shown in Fig. 9(a). The bamboo material was placed in the core layer, and the mechanical properties of the hemlock on the surface layer to form CLT were lower, as shown in Fig. 9(b). The clear damages of the bending specimens as shown in Fig. 10. The tensile strength of the hemlock in the surface layer of WBWCLT was low, and the failure mode in the bending was characterized by tensile fracture damage, which was superior to the BWB. In the area between the support and the loading rolls, BCLT first underwent shear failure of the transverse layer. At the same time as the shear failure of the transverse layer, the load applied to the test piece reached its

\begin{tabular}{|c|c|c|c|c|c|c|c|}
\hline $\begin{array}{l}\text { BWBCLT } \\
\text { Samples }\end{array}$ & $\begin{array}{l}\mathrm{MOE} \\
(\mathrm{MPa})\end{array}$ & $\begin{array}{l}\text { MOR } \\
(\mathrm{MPa})\end{array}$ & $\begin{array}{l}\text { Maximum } \\
\text { Load }\end{array}$ & $\begin{array}{c}\text { WBWCLT } \\
\text { Samples }\end{array}$ & $\begin{array}{l}\text { MOE } \\
(\mathrm{MPa})\end{array}$ & $\begin{array}{l}\text { MOR } \\
(\mathrm{MPa})\end{array}$ & $\begin{array}{l}\text { Maximum } \\
\text { Load }\end{array}$ \\
\hline 1 & 8777 & 37.6 & 2007 & 1 & 6755 & 40.5 & 2782 \\
\hline 2 & 8283 & 49.7 & 2654 & 2 & 6213 & 35.2 & 2416 \\
\hline 3 & 10749 & 42.2 & 2251 & 3 & 6262 & 38.8 & 2665 \\
\hline 4 & 10305 & 34.7 & 1851 & 4 & 5818 & 33.8 & 2318 \\
\hline 5 & 9072 & 40.5 & 2163 & 5 & 5769 & 27.6 & 1893 \\
\hline 6 & 9615 & 47.5 & 2537 & 6 & 6656 & 49.0 & 3297 \\
\hline 7 & 9368 & 38.0 & 2029 & 7 & 4793 & 25.8 & 1769 \\
\hline AV & 9454 & 41.5 & 2213 & AV & 6038 & 35.8 & 2449 \\
\hline SD & 857 & 5.46 & 291 & SD & 664 & 7.95 & 527 \\
\hline CV\% & $9.05 \%$ & $13.1 \%$ & $13.2 \%$ & CV\% & $11 \%$ & $22.1 \%$ & $21.5 \%$ \\
\hline
\end{tabular}
maximum value.

Table 3. Bending Data

Note: AV is Average, SD is standard deviation, and CV is coefficient of variation 


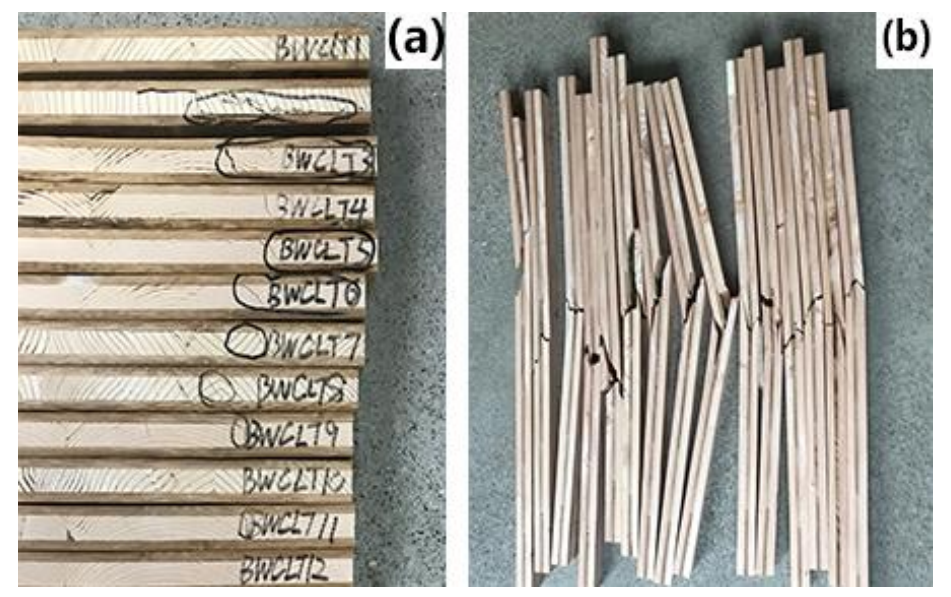

Fig. 9. Damage of actual bending test: (a) BWB damage and (b) WBW damage (The thickness of bamboo board is $6 \mathrm{~mm}$, and that of hemlock is $15 \mathrm{~mm}$.)

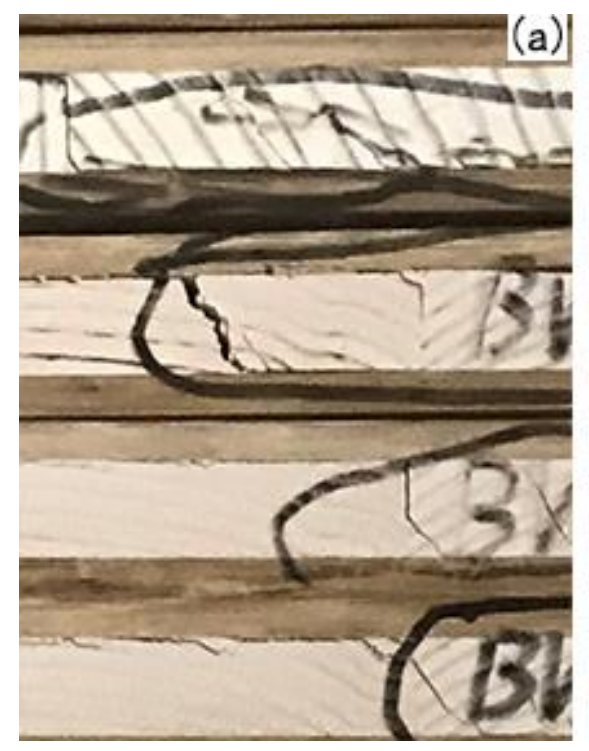

Fig. 10. Clear damages of the bending specimens:

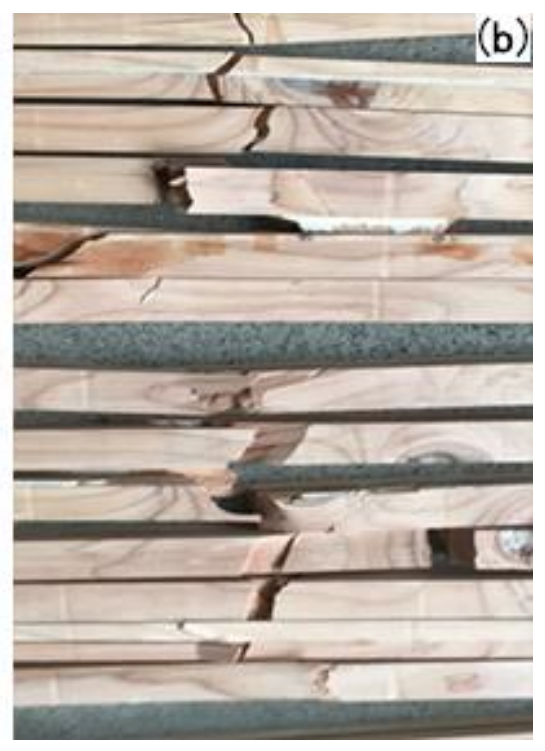

(a) BWB damage and (b) WBW damage.

Through analyzing the physical characteristics of bamboo and wood, the bamboo was found to have high strength, high hardness, good toughness, wear resistance, and biodegradability. Hemlock had the advantages of a good MOE, but at the same time, it also had the disadvantages of poor mechanical strength, low surface hardness, high residual stress, and it was not suitable for engineering structural timber. The average static bending strength of BWBCLT was 5.65 MPa higher than that of WBWCLT.

\section{Numerical Simulation Results of CLT Samples}

A four-point bending simulation of the numerical model of the BCLT sample by ABAQUS is presented in Fig. 11. The maximum stress, maximum load, and loaddisplacement curve were extracted from the post-processing results. The maximum stress of the BWBCLT was 72.9 MPa, the maximum load was $2630 \mathrm{~N}$, and the average load of the BWBCLT experiment was $2210 \mathrm{~N}$. The wood was an orthotropic material, which was more complex than traditional isotropic material, and the finite element simulation was an ideal homogeneous material. It was difficult to simulate the real material in the software. 
It has little effect on the simulation of material's elastic stage, but it is impossible to simulate the material's plasticity and damage stage. Therefore, the result of finite element simulation was $421 \mathrm{~N}$ higher than that of the experiment.

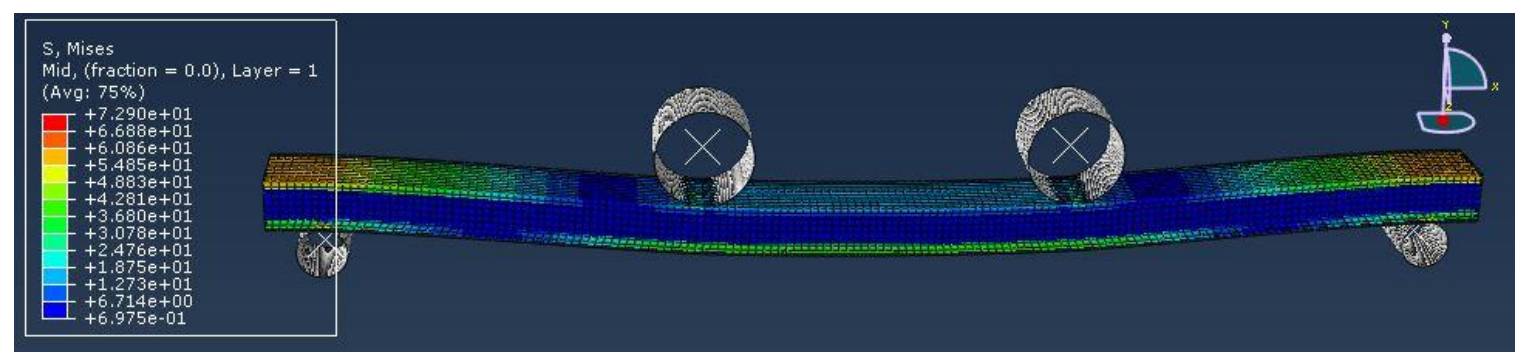

Fig. 11. Finite element bending simulation results

\section{Comparison}

The load-displacement curves of BCLT samples were compared, as shown in Fig. 12. The error coefficient between the two was calculated using the cost function $\mathrm{J}$ (Eq. 6). The interval between points was $0.5 \mathrm{~mm}$ ( $\mathrm{m}$ is 36 ), the error coefficient was 0.2988 when the displacement was $18 \mathrm{~mm}$, and the minimum error coefficient was 0.0015 when the displacement was $12 \mathrm{~mm}$. In the finite element simulation, only the elastic constants of the material were inputted, and the results of the elastic constants of the material showed a linear phase at the beginning of the curve. Both had the same general trend. Under certain conditions, the finite element software ABAQUS could simulate the actual bending test. Equation 6 is as follows,

$$
J(\theta)=\frac{1}{2 m} \sum_{i=1}^{m}(Y(i)-y(i))^{2}
$$

where $Y(i)$ is a function of the actual experiment, $y(i)$ is a function of the finite element simulation, $i$ is comparison points, and $m$ is the number of comparison points.

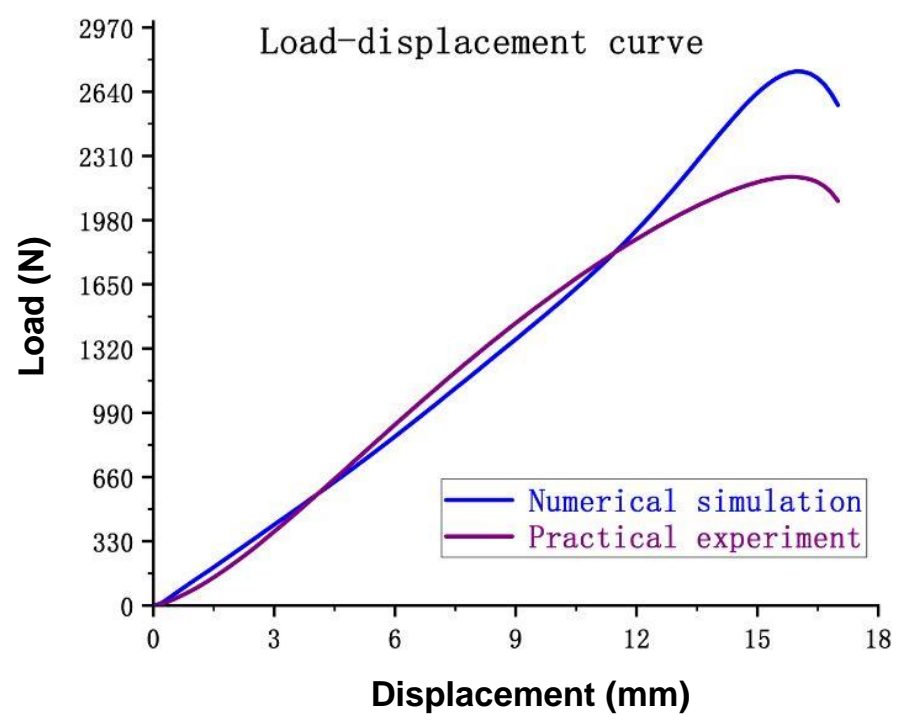

Fig. 12. Load-displacement curve 


\section{Mechanical Properties of BWCLT Board}

Numerical simulation results of BWCLT board

In the finite element software ABAQUS, the numerical model of BWCLT boards were simulated by four-point bending, and the stress distribution was obtained as shown in Fig. 13. The maximum stress and load were extracted from the post-processing results for analysis. To better analyze the results, the key data of eight combinations were integrated, as listed in Table 4. The eight combinations of BWCLT boards were under the same constraints. When the bamboo arrangement was the same and only the arrangement of the hemlock was changed, the stress difference between the combinations was $0.4 \mathrm{MPa}$, and the load difference was $500 \mathrm{~N}$. The third combination CLT1-2-1 (i.e., the upper and lower layers of the bamboo were Arrangement 1 and the hemlock was Arrangement 2) had a maximum load of $57,700 \mathrm{~N}$ and a maximum stress of $103.9 \mathrm{MPa}$. The second combination CLT1-1-2 (i.e., the upper layer of the bamboo and the hemlock was Arrangement 1, and the lower layer of bamboo was Arrangement 2) had a maximum load of 54,760 N and a maximum stress of 89.0 MPa. The stress difference between the two was $14.94 \mathrm{MPa}$, and the load difference was $2920 \mathrm{~N}$. The overall mechanical properties of CLT1-2-1 were better.

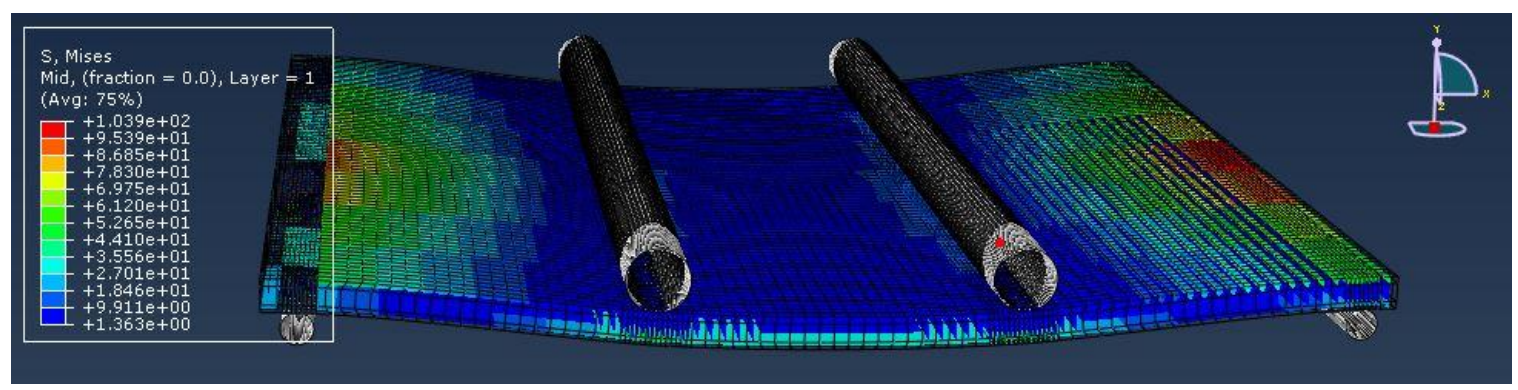

Fig. 13. Simulation results of bending of BWCLT board

Table 4. Bending Experiment Results of BWCLT Board

\begin{tabular}{|c|c|c|}
\hline \multicolumn{1}{c}{$\begin{array}{c}\text { CLT } \\
\text { Combination }\end{array}$} & $\begin{array}{c}\text { Maximum } \\
\text { Stress } \\
(\mathrm{MPa})\end{array}$ & $\begin{array}{c}\text { Maximum } \\
\text { Load (N) }\end{array}$ \\
\hline $1-1-1$ & 103.5 & 57123 \\
\hline $1-1-2$ & 88.96 & 54762 \\
\hline $1-2-1$ & 103.9 & 57682 \\
\hline $1-2-2$ & 89.32 & 55230 \\
\hline $2-1-1$ & 89.28 & 55995 \\
\hline $2-1-2$ & 102.2 & 55797 \\
\hline $2-2-1$ & 89.63 & 56515 \\
\hline $2-2-2$ & 102.7 & 56329 \\
\hline Average & 96.18 & 56179 \\
\hline
\end{tabular}

\section{Experimental and Finite Element Comparisons}

The load-displacement curves of BCLT samples were compared, as shown in Fig. 14. The error between the two was calculated using the cost function $J$ (Eq. 6). The interval 
between the two points was still $0.5 \mathrm{~mm}$ ( $\mathrm{m}$ is 66 ), the error coefficient was 3.7721 when the displacement was $32 \mathrm{~mm}$, and the error coefficient reached the minimal value 0.0194 and 0.3122 when displacement was $9 \mathrm{~mm}$ and $22 \mathrm{~mm}$, respectively. The error coefficient was still smaller in the linear phase.

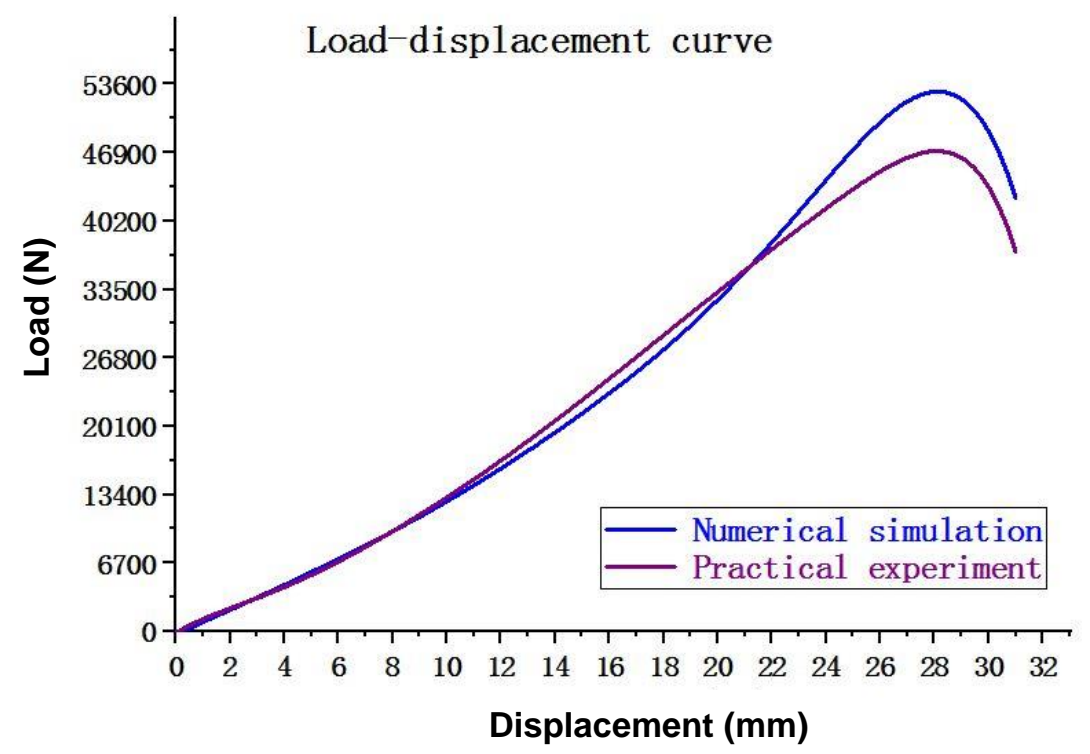

Fig. 14. Load-displacement comparison

\section{CONCLUSIONS}

1. For the BCLT samples, the maximum load values of BWB and WBW had a difference of $236 \mathrm{~N}$. The bending test results showed that the WBW had low tensile strength. The BWB damage showed rolling shear of the core layer of hemlock, and the upper and lower bamboo boards were still in the elastic range, and without major damage, they could continue to withstand the force. Considering the strength, resources, and growth cycle of the actual materials, the combination of BWB was more economical.

2. Comparing the actual four-point bending experiment with the finite element numerical simulation, the error coefficient was 0.0178 when the maximum load was reached, and the error coefficient was the minimum at $12 \mathrm{~mm}$ displacement, which was 0.0015 . The total error coefficient of the BWCLT board was 3.7721 when the force displacement was $32 \mathrm{~mm}$. The results showed that it was feasible to use the finite element software for a numerical simulation bending test.

3. Different combinations of BWCLT boards were used under the same constraints. When the arrangement of the hemlock was changed, the stress difference between the combinations was $0.4 \mathrm{MPa}$, and the load difference was $500 \mathrm{~N}$. The third combination CLT1-2-1 (i.e., the upper and lower layers of the bamboo were Arrangement 1 and the hemlock was Arrangement 2) had a maximum load of $57682 \mathrm{~N}$ and a maximum stress of 103.9 MPa. The overall mechanical properties of CLT1-2-1 were better. 


\section{ACKNOWLEDGEMENTS}

The authors would like to thank for the Program of National Natural Science Foundation of China (CN) [grant number 31700643], and the Postdoctoral fund of Heilongjiang [grant number LBH-Q18006].

\section{REFERENCES CITED}

Bejtka, I. (2011). Cross (CLT) and Diagonal (DLT) Laminated Timber as Innovative Material for Beam Elements, Kit Scientific Publishing, Karlsruhe, Germany.

Brandner, R., Flatscher, G., Ringhofer, A., Schickhofer, G., and Thiel, A. (2016). "Cross laminated timber (CLT): Overview and development," European Journal of Wood and Wood Products 74(3), 331-351. DOI: 10.1007/s00107-015-0999-5

Buchanan, A. H. (2000). "Fire performance of timber construction," Progress in Structural Engineering and Materials 2(3), 278-289. DOI: 10.1002/15282716(200007/09)2:3<278::AID-PSE33>3.0.CO;2-P

Chen, J. Y. (2009). Development of Cross Lamination Technology for MPB Engineered Wood Products-Thick Laminated MPB Wood Plates (Technical Report for Forestry Innovation Investment Ltd.), University of British Columbia, Vancouver, B.C., Canada.

Dias, A. M. P. G., Lopes, S. M. R., Van de Kuilen, J.-W. G., and Cruz, H. M. P. (2007). "Load-carrying capacity of timber-concrete joints with dowel-type fasteners," Journal of Structural Engineering 133(5), 720-727. DOI: 10.1061/(asce)07339445(2007)133:5(720)

EN 16351 (2015). "Timber structures — Cross laminated timber — Requirements," European Committee for Standardization, Brussels, Belgium.

Fang, C.-H., Jiang, Z.-H., Sun, Z.-J., Liu, H.-R., Zhang, X.-B., and Zhang, R., and Fei, B.-H. (2018). "An overview on bamboo culm flattening," Construction and Building Materials 171, 65-74. DOI: 10.1016/j.conbuildmat.2018.03.085

FPInnovations (2011). CLT Handbook: Cross-Laminated, FPInnovations, Quebec, Canada.

Frangi, A., Schleifer, V., Fontana, M., and Hugi, E. (2010). "Experimental and numerical analysis of gypsum plasterboards in fire," Fire Technology 46(1), 149-167. DOI: 10.1007/s10694-009-0097-5

GB/T 1931 (2009). "Method for determination of moisture content of wood," Standardization Administration of China, Beijing, China.

GB/T 1933 (2009). "Method for determination of wood density," Standardization Administration of China, Beijing, China.

GB/T 17657 (2013). "Test method for physical and chemical properties of wood-based panels and decorated panels," Standardization Administration of China, Beijing, China.

Gong, Y., Wu, G., and Xu, J. (2018). "Bending properties of cross-laminated timber fabricated with Larix kaempferi," Journal of Northwest A \& F University (Natural Science Edition) 46(11), 25-30. DOI: 10.13207/j.cnki.jnwafu.2018.11.004

He, M., Xiaofeng, S., and Li, Z. (2018). "Bending and compressive properties of crosslaminated timber (CLT) panels made from Canadian hemlock," Construction and Building Materials 185, 175-183. DOI: 10.1016/j.conbuildmat.2018.07.072 
Jiang, Z.-H., Wang, G., Fei, B.-H., and Yu, W.-J. (2002). “The research and development on bamboo/wood composite materials," Forest Research 15(6), 712-718.

Li, X. Z., Xu, M., Cai, Y., Ren, H., Q., and Zhong, Y. (2015). "Determination of elastic constants of recombinant bamboo for structural material using an electrical measurement method," Journal of Anhui Agricultural University 42(5), 756-760. DOI: 10.13610/j.cnki.1672-352x.20150825.015

Pina, J. C., Saavedra Flores, E. I., and Saavedra, K. (2019). "Numerical study on the elastic buckling of cross-laminated timber walls subject to compression," Construction and Building Materials 199, 82-91. DOI:

10.1016/j.conbuildmat.2018.12.013

Schneider, J., Shen, Y., Stiemer, S. F., and Tesfamariam, S. (2015) "Assessment and comparison of experimental and numerical model studies of cross-laminated timber mechanical connections under cyclic loading," Construction and Building Materials 77, 197-212. DOI: 10.1016/j.conbuildmat.2014.12.029

Sebera, V., Muszyński, L., Tippner, J., Noyel, M., Pisaneschi, T., and Sundberg, B. (2015). "FE analysis of CLT panel subjected to torsion and verified by DIC," Materials and Structures 48(1-2), 451-459. DOI: 10.1617/s11527-013-0195-1

Sikora, K. S., McPolin, D. O., and Harte, A. M. (2016). "Effects of the thickness of crosslaminated timber (CLT) panels made from Irish Sitka spruce on mechanical performance in bending and shear," Construction and Building Materials 116, 141150. DOI: 10.1016/j.conbuildmat.2016.04.145

Wang, Z., Zhou, J., Dong, W., Yao, Y., and Gong, M. (2018). "Influence of technical characteristics on the rolling shear properties of cross laminated timber by modified planar shear tests," Maderas. Ciencia y Technología 20(3), 469-478. DOI: 10.4067/S0718-221X2018005031601

Wang, Z. Q., Fu, H. M., Dai, X. H., Na, B., and Lu, X. N. (2014). "Experimental study on mechanical properties of cross-laminated timber with different tree species wood," Journal of Central South University of Forestry and Technology 34(12), 141-145. DOI: 10.14067/j.cnki.1673-923x.2014.12.025

Wang, Z. Q., Hao, Z., Juncheng, Y., Bin, N., Peng, W. (2016). "Testing and analysis of thermal performance of orthogonal plywood walls," New Building Materials 43(6), 69-71. DOI: 10.3969/j.issn.1001-702X.2016.06.019

Xie, W. B., Wang, Z., Gao, Z. Z., and Wang, J. H. (2018). "Performance test and analysis of cross-laminated timber (CLT)," China Forest Products Industry 45(10), 44-49, +53 .

Yao, L. U., Min-Min, L. I., Zheng, W., Zi-Zhen, G., and Jian-He, W. (2018).

"Calculation and analysis of mechanical properties of three layers cross-laminated timber of full-size hemlock," Journal of Northwest Forestry University 33(6), 231235.

Article submitted: November 20, 2019; Peer review completed: January 24, 2020; Revised version received: April 19, 2020; Accepted: May 21, 2020; Published: May 27, 2020.

DOI: $10.15376 /$ biores.15.3.5417-5432 